\title{
Geoengineering: An Idea Whose Time Has Come?
}

\author{
David B. Resnik ${ }^{1,{ }^{*}}$ and Daniel A. Vallero ${ }^{2}$ \\ ${ }^{1}$ National Institute of Environmental Health Sciences, National Institutes of Health, Box 12233, \\ Mail Drop CU-03, Research Triangle Park, NC, 27709, USA \\ ${ }^{2}$ Pratt School of Engineering, Duke University, USA
}

\begin{abstract}
Some engineers and scientists recently have suggested that it would be prudent to consider engaging in geoengineering to mitigate global warming. Geoengineering differs from other methods for mitigating global warming because it involves a deliberate effort to affect the climate at a global scale. Although geoengineering is not a new idea, it has taken on added significance as a result of difficulties with implementing other proposals to mitigate climate change. While proponents of geoengineering admit that it can have significant risks for the environment and public health, many maintain that it is worth pursuing, given the failure of other means of mitigating global warming. Some environmental groups have voiced strong opposition to all forms of geoengineering. In this article, we examine arguments for and against geoengineering and discuss some policy options. We argue that specific geoengineering proposals should not be implemented until there is good evidence concerning their safety, efficacy, and feasibility, as well as a plan for oversight. International cooperation and public input should also be sought. Other methods for mitigating global warming should be aggressively pursued while geoengineering is under consideration. The promise of an engineering solution to global warming should not be used as an excuse to abandon or cut back current, climate mitigation efforts.
\end{abstract}

\section{Keywords}

Global warming; Geoengineering; Climate mitigation; Ethics; Policy; Risk

\section{Introduction}

\begin{abstract}
Recently, some engineers and scientists have suggested that it would be prudent to consider engaging in planetary-scale interventions, so called "geoengineering," to mitigate global climate change and global warming. Geoengineering differs from other methods for mitigating global warming because it involves a deliberate effort to affect the climate at a global scale. Although geoengineering is not a new idea, it has taken on added significance as a result of difficulties with implementing other proposals to mitigate climate change. While proponents of geoengineering admit that these measures pose significant risks to the environment and public health, they maintain that they are well worth pursuing, given the failure of other means of mitigating global warming. Conversely, some environmental groups have voiced strong opposition to all forms of geoengineering. In this article, we
\end{abstract}

Copyright: (C) 2011 Resnik DB, et al.

*Corresponding author: David B. Resnik JD, National Institute of Environmental Health Sciences, National Institutes of Health, Box 12233, Mail Drop CU-03, Research Triangle Park, NC, 27709, USA, Tel: (919) 541-5658; Fax: (919) 541-9854;

Resnikd@niehs.nih.gov.

Publisher's Disclaimer: This is an open-access article distributed under the terms of the Creative Commons Attribution License, which permits unrestricted use, distribution, and reproduction in any medium, provided the original author and source are credited. 
review the arguments for and against geoengineering and discuss some policy options. We argue that geoengineering research should continue, but that specific proposals should not be implemented until we have a better understanding of the risks, costs, and practical and political problems associated with geoengineering.

\section{The Problem of Global Warming}

Since the 1980s, a scientific consensus has emerged that human activities play a significant role in warming the climate [1]. Global surface temperatures increased $0.74^{\circ} \mathrm{C}$ between 1906 and 2005. Eleven of the twelve years between 1993 and 2006 had the highest recorded surface temperatures since 1850 [2]. 2005 and 2010 were the hottest years on record [3]. Sea levels have risen about $1.8 \mathrm{~mm}$ per year since 1961 , and $3.1 \mathrm{~mm}$ per year since 1993 , due to melting ice from polar ice sheets and glaciers [2]. The production of greenhouse gases, chiefly carbon dioxide $\left(\mathrm{CO}_{2}\right)$ and methane $\left(\mathrm{CH}_{4}\right)$, is largely responsible for the increase in global temperatures [2]. Greenhouse gases warm the Earth by preventing solar radiation from being reflected into outer space. Increased concentrations of greenhouse gases in the atmosphere are associated with global warming. Anthropogenic greenhouse gases, which have risen steadily since 1750, increased $70 \%$ from 1970 to 2004 [2]. Numerous human activities, including transportation, manufacturing, urban development, indoor heating, electric power generation, and agriculture, produce greenhouse gases.

If no actions are taken to stabilize or reduce emissions of anthropogenic greenhouse gases, global temperatures and sea levels may continue to rise [2]. According to various estimates, average global temperatures can be expected to rise between $1.1^{\circ} \mathrm{C}$ and $6.4^{\circ} \mathrm{C}$ in the next century, and sea levels will rise between 0.18 and 0.59 meters, unless steps are taken to stabilize greenhouse gas emissions. Global temperatures and sea levels will continue to rise even if greenhouse gas emissions remain at current levels, due to time lags between greenhouse gas levels and geological and biological responses, such as removal of $\mathrm{CO}_{2}$ from the air by plants [2].

Much of the debate within the scientific community has involved two aspects of climate change. First, how much of the observed and projected mean global temperature increase is the result of human activities (e.g. anthropogenic sources of greenhouse gases)? Second, how confident are we in estimating future global climate? We acknowledge this debate and are not ignoring recent controversies regarding the data and models being used. In fact, global climate change is similar to other modeling efforts in that accuracy of prediction depends on the quality and representativeness of the data and the algorithms. Errors in assumptions and improper weighting of variables will lead to incorrect predictions. Thus, policy makers are looking to engineers and scientists to evaluate the state-of-the-science for predicting future climate.

Presently, environmental and health policies are made from two perspectives: evidencebased risk assessments or precaution. Risk assessments require information on both the hazard and the likelihood of exposure to that hazard. Thus, if this information is scarce or unreliable, the risk assessment is useless at best and dangerous at worst, since it either underestimates or overestimates the risk. For problems that may affect large numbers of people, large geographic areas, and/ or which are irreversible, precaution is in order. This is the basis for factors of safety in engineering design. Therefore, precaution applies to estimates of global climate change (see Figure 1) [4].

\section{Adverse Consequences of Global Warming}

Global warming is expected to have numerous adverse consequences for human health and well being and the environment, such as: 
- Increased flooding in coastal areas, with potentially devastating impacts on coastal cities and island nations [2]

- Increased frequency and strength of tropical storms, which produce flooding, property damage, and loss of life [2]

- $\quad$ Flooding in regions at higher altitudes, due to increased precipitation, and droughts in subtropical regions, due to decreased precipitation [5]

- Increased risk of famine and malnutrition in drought-stricken areas [5]

- Decreased availability of clean drinking water in areas affected by droughts [5]

- Increased forest fires as a result of drought and heat [2]

- Higher mortality and morbidity due to heat stroke and heat prostration during the summer months [2]

- Increased prevalence of water-borne and mosquito-borne diseases due to flooding [6]

- Increased ocean algal blooms, which will have adverse effects on fish population and human health Interagency [6]

- Increased prevalence of some infectious diseases as a result of changing geographic distributions of species that transmit pathogens to humans [6]

- Increased respiratory problems due to higher levels of ozone and allergens [6].

\section{Responding to Climate Change}

There are two basic policy options for responding to global warming: mitigation and adaptation [7]. Mitigation includes efforts to prevent or minimize climate change, including:

- Regulations to control greenhouse gas emissions, notably $\mathrm{CO}_{2}$. These include direct controls, such as emission limits at each source, and indirect methods, such as carbon taxes or cap-and-trade systems, in which the total level of $\mathrm{CO}_{2}$ in a nation is capped and large polluters purchase rights to emit $\mathrm{CO}_{2}$, which can be traded [8]

- Tax breaks and other market-based incentives for developing and using alternatives to fossil fuels, such as wind, solar, hydroelectric, geothermal, and nuclear power [8]

- $\quad$ Regulations mandating higher fuel economy standards for automobiles and increased energy efficiency for appliances, heating and cooling systems, and electric lighting [8]

- $\quad$ Public support for mass transit, carpooling, biking, and other forms of transportation that save energy [7]

- $\quad$ Telecommuting, teleconferencing, and videoconferencing [7]

- $\quad$ Protection of forests, which remove $\mathrm{CO}_{2}$ from the atmosphere [7]

- Developing trees that are more efficient at removing $\mathrm{CO}_{2}$ from the atmosphere and storing carbon in biomass [9]

- Reduction in the consumption of meat, since the livestock industry is a significant source of greenhouse gases (particularly $\mathrm{CO}_{2}$ and methane $\mathrm{CH}_{4}$ ) and contributes to deforestation [10]

- Pollution prevention and sustainable design of products, where certain processes (e.g. combustion) are minimized or eliminated [11] 
- Control of population growth and development [12].

Adaptation includes steps taken to adjust to or compensate for the effects of global warming, such as making preparations for tropical storms, floods, and heat waves; protecting coastal regions from rising sea levels; developing and growing drought-resistant crops; increasing drinking water supplies; and enhancing infectious diseases surveillance and response $[7,13,14]$.

Thus far, efforts to mitigate global warming have been largely ineffective [15]. Although policymakers and citizens have understood the importance of responding to the problem of climate change for at least two decades, global greenhouse gas emissions from human sources have continued to increase at roughly the same rate in the 2000s as they did in the 1990s and show no signs of abating unless some decisive steps are taken [7].

\section{Difficulties with Climate Change Mitigation}

There are several reasons why mitigating global warming has proven to be very difficult. First, most of the proposed mitigation strategies require significant changes in human behavior. Individuals must be willing to drive less, use fuel efficient cars, seek alternatives to fossil fuels, save energy, eat less meat, and control population and development. Taking the steps necessary to mitigate global warming requires sacrifices that many people are not willing to make. There is a cruel irony here similar to case of the Prisoner's dilemma: by acting according to what they perceive to be in their own interests, individuals may produce an outcome that is not in society's interests. Only by cooperating can individuals produce an outcome that is beneficial to all [16].

The Prisoner's dilemma analogy applies to global problems in a number of ways. The population that benefits from the direct impacts of climate change can be distinct from the population that must mitigate it. For example, rising sea levels may not have much meaning for a person living in Kansas, who is asked to eat less meat, but would have a significant impact on islanders who live just above sea level. Ironically, many of the islanders' lifestyles contribute very little to anthropogenic greenhouse gas releases. Another important point is that cause and effect are temporally separated. Some have considered the importance of considering distant and future peoples, for example, in engineering ethics [17]. This is difficult to do, however, in typical risk-benefit analysis, such as when a highlevel nuclear waste disposal site must be designed to guard against breeches that could occur over the next million years.

The second factor diminishing the utility of mitigation is the potential of concomitant adverse socioeconomic impacts. Proposed policies may have adverse economic impacts that nations are not willing to accept. Cap-and-trade systems or carbon taxes would increase energy costs until alternative sources of energy become economical, which could take decades. Increases in energy costs would affect the price of transportation, manufacturing, food, health care, and many other goods and services. These price increases could contribute to inflation, and undermine economic growth and lead to job losses [18]. According to the Heritage Foundation, a cap and trade system for controlling $\mathrm{CO}_{2}$ emissions would lead to a $\$ 4.8$ trillion reduction in gross domestic product in the U.S. and a loss of three million manufacturing jobs [19]. Some argue, however, that these adverse economic losses would be offset by gains in new jobs related to alternative energy production as well as the benefits of avoiding a rise in global temperatures [20]. Though it is far from certain that global warming mitigation policies will have the dire economic consequences predicted by some, there may be little political will, especially in these difficult economic times, to embrace policies that could have short-term negative economic impacts. 
Third, since climate change is a global problem, effective mitigation requires a high degree of international cooperation, which may be difficult to achieve, especially if countries do not view mitigation as in their collective interests. The Kyoto Protocol is the most significant climate change treaty approved to date and calls for industrialized nations to reduce their greenhouse gas emissions to 5\% below 1990 levels [8]. Through use of a cap-and-trade system, $\mathrm{CO}_{2}$ emissions in a country would be capped, and large polluters would purchase emission permits from the government, which they could trade. The working assumption of cap-and-trade is that a free market in $\mathrm{CO}_{2}$ emissions would encourage investment and innovation concerning $\mathrm{CO}_{2}$ emission control, because companies would want to reduce the need for costly permits. The cap could be gradually lowered over time to reduce overall emissions [21]. Though 190 nations signed the Kyoto Protocol, the U.S. did not, due to concerns about its economic impacts and the fact that two other major greenhouse gas producers, China and India, also did not sign the treaty [22].

Another key issue is whether industrialized nations should bear the entire burden of climate change mitigation [23]. Developing nations have argued that they should not have to control their greenhouse gas emissions, because they contribute a small percentage to the world's total, and because they are still developing economically and need to be spared the burden of climate change mitigation costs. Industrialized nations have argued that all nations, including developing ones, should do their part to mitigate climate change [22]. Though there are efforts to negotiate a new climate change treaty, no agreement has been reached so far [24].

Fourth, climate change science has been mired in politics [25]. Global warming skeptics have challenged the scientific consensus. Some have argued that global warming is not really occurring. Others acknowledge that the planet is getting warmer but they argue that human activities are not primarily responsible [26]. Some agree that global warming is occurring and that human activities are largely responsible, but they challenge predictions concerning the impacts of global warming on public health, the economy, and the environment [27]. Political and economic interests have fueled much of the skepticism concerning climate change. The administration of U.S. President George W. Bush did not accept the scientific consensus on climate change and resisted efforts to implement policies designed to mitigate global warming. U.S. government officials censored government funded reports on climate change and intimidated government scientists who spoke out about global warming [28]. The Administration's stance on climate change was due, in part, to its alignment with business and industry groups, which opposed climate change mitigation on economic grounds. Many skeptics are funded by business and industry groups opposed to climate change mitigation policies, such as cap-and-trade systems or carbon taxes [25]. Climate change has become an issue in the 2012 U.S. Presidential race, and some candidates have expressed strong doubts about anthropogenic global warming [29].

The politics of global warming affects research funding. When most scientists accept global warming, it becomes more difficult to receive government funding for research that challenges this paradigm. Hence, much of the funding for research that challenges climate change orthodoxy has come from private sources, which enhances the perception that the science is tainted. For constructive criticism to occur, funding disparities in climate change research must be addressed.

Even without the political and economic issues, modeling future events is highly uncertain. We may all agree that concentrations of greenhouse gases have increased in recent decades, but the relationship between these increases and climate change is not direct. For example, increasing $\mathrm{CO}_{2}$ may be accompanied by changes in the carbon cycle, including increased photosynthesis and trophic status of ecosystems. The modeling must account for these 
changes, such as mitigation of warming by larger vegetative covers, changes in cloud coverage, etc. Any scientific model propagates uncertainty. The more complicated the system, like those in the hydrosphere and troposphere, the more uncertainty in prediction.

\section{Geoengineering}

Since current attempts to mitigate global warming have not been successful, and face significant social, political and economic challenges, some environmental scientists have urged policymakers to consider an alternative approach to mitigation, known as geoengineering [15,30-34]. Though human activity has been unintentionally changing the climate for hundreds of years through the production of greenhouse gases and deforestation, geoengineering would be an effort to use various technologies to deliberately change the climate at a global scale in order to mitigate global warming [35]. Geoengineering is not a new idea - it has been discussed since the 1990s [30,36,37]- but it has taken on a new urgency as efforts to mitigate global warming have faltered. Geoengineering should be distinguished from other forms of mitigation, such as reduction in $\mathrm{CO}_{2}$ emissions or protection of forests, which do not involve global scale interventions in the climate [35]. Many who favor geoengineering do not oppose other mitigation strategies, but acknowledge these efforts may not be effective. Faced with the prospect of potentially calamitous climate change, some view geoengineering as the lesser of two evils [15,30].

Two types of geoengineering have been discussed and debated: $\mathrm{CO}_{2}$ removal and solar radiation management (see Table 1). $\mathrm{CO}_{2}$ removal deals with one of the primary causes of climate change-excess levels of greenhouse gases and involves methods for extracting $\mathrm{CO}_{2}$ from the atmosphere and storing or sequestering it. Solar radiation management does not attempt to deal with the underlying causes of climate change. It attempts to counteract increases in greenhouse gases by blocking solar radiation or increasing the reflectivity of clouds on the Earth's surface.

It should be noted that what is classified as geoengineering is subject to debate. For example, the Intergovernmental Panel on Climate Change devotes an entire special report to capturing $\mathrm{CO}_{2}$ in geologic and oceanic reservoirs [38]. This effort is just as ambitious and at the same scale as many geoengineering projects that are deemed by the majority of the scientific community to be too risky or too uncertain. The difference between capturing $\mathrm{CO}_{2}$ and the geoengineering proposals discussed here may be only a matter of degree.

We will not discuss all of the various proposals in detail (see [35] for review). Instead, we will assess two proposals for blocking solar radiation, one put forth by Nobel Prize-winning, atmospheric geochemist Paul Crutzen in 2006 and a variation on his proposal [15]. Crutzen has helped to legitimize research on geoengineering as a highly respected scientist who has championed many different environmental causes [39]. Crutzen's idea is based on the observation that sulfate particles in the atmosphere increase cloud albedo, which helps to reflect solar radiation into space [15]. The eruption of Mount Pinatubo in 1991 provides striking evidence of the effects of sulfate particles in the atmosphere. The volcano emitted 10 million metric tons of sulfur dioxide $\left(\mathrm{SO}_{2}\right)$ into the stratosphere, which was converted to sulfate particles. The resulting enhancement of cloud albedo cooled the Earth by $0.5^{\circ} \mathrm{C}$ [15]. Crutzen's proposal is to use airplanes to spray $\mathrm{SO}_{2}$ into the stratosphere to induce cloud albedo and cool the planet. He argues that it would be preferable to spray $\mathrm{SO}_{2}$ in the stratosphere rather than the troposphere, because sulfate particles last longer in the stratosphere (1-2 years) and have a greater impact on cloud albedo. The amount of $\mathrm{SO}_{2}$ required, 2 million metric tons, would be only about $3.6 \%$ of the 55 million metric tons of $\mathrm{SO}_{2}$ emitted into the atmosphere each year from the burning of fossil fuels. Crutzen estimates that it would cost $\$ 25-\$ 50$ billion per year to inject enough $\mathrm{SO}_{2}$ into the 
stratosphere to mitigate climate change, but this cost rises when greenhouse gas emissions increase [15].

Crutzen's proposal might be effective and could be implemented quickly, but it has some potential risks, which he readily acknowledges, because it may adversely impact human health and the environment $[35,39,40]$. First, $\mathrm{SO}_{2}$ is considered to be an air pollutant, and it is regulated in the U.S. by the Environmental Protection Agency (EPA) under the Clean Air Act [41]. $\mathrm{SO}_{2}$ exposure contributes to respiratory problems, such as airway constriction and asthma exacerbation [41]. Short-term exposure is associated with increased visits to emergency departments and hospitalization for respiratory problems, especially among young children and asthmatics [41]. It is not known how the EPA would respond to Crutzen's proposal or whether the amount of $\mathrm{SO}_{2}$ injected into the stratosphere would violate EPA rules.

Second, spraying $\mathrm{SO}_{2}$ into the stratosphere can also interfere with ozone chemistry, which could cause thinning of the protective ozone layer [42]. The ozone layer protects all life forms from harmful ultraviolet light radiation, which causes skin cancer.

Third, $\mathrm{SO}_{2}$ is converted into sulfuric acid in the atmosphere and falls to the Earth as acid rain. Acid rain lowers the $\mathrm{pH}$ of the soil, which has adverse impacts on plants species that cannot tolerate higher acidity and can impact ecosystems [42,43].

Fourth, $\mathrm{SO}_{2}$ spraying would stabilize climate at higher levels of atmospheric $\mathrm{CO}_{2}$ than occur today. When carbon dioxide dissolves in the sea, it reacts with water to form free carbon dioxide, carbolic acid and bicarbonate. The net effect of this reaction increases the acidity of water. The oceans have increased in acidity since 1750, due to increases in anthropogenic carbon dioxide in the atmosphere [5]. An increase in the acidity of sea water decreases the availability of calcium carbonate and threatens species that form shells from this compound, such as mollusks, corals, and some types of plankton. A reduction in these species could have wide-ranging impacts on other marine species and ecosystems, since many organisms feed on mollusks or plankton or depend on coral reefs for shelter $[44,45]$.

Fifth, enhancement of cloud albedo to stabilize global temperatures could affect precipitation patterns, tropical storm activity, temperature distribution, and wind $[32,45]$.

Sixth, a significant percentage of the radiation reflected by sulfate particles strikes the Earth as diffuse light. This effect increases the whiteness of the daytime sky and may reduce the efficiency of plant photosynthesis and solar power $[45,46]$.

Seventh, if we miscalculate and spray too much $\mathrm{SO}_{2}$ into the stratosphere, this could lead to excessive cooling and trigger an ice age [45].

Keith has proposed a different form of albedo enhancement as an alternative to Crutzen's proposal [46]. Keith proposes that disc-shaped, engineered nanoparticles, composed of layers of aluminum oxide, metallic aluminum, and barium titanate, be released into the stratosphere. The particles would take advantage of photophoretic and electromagnetic forces to levitate above the stratosphere. (Photophoretic forces occur when there is a temperature differential between an aerosol and the surrounding gas). A chief advantage of these nanoparticles is that they remain in the atmosphere longer than $\mathrm{SO}_{2}$. Their specific reflective properties could also be controlled through engineering and design, so that they would produce the correct amount of diffuse light. Since they would be above the stratosphere, they would not interfere with ozone chemistry [46]. Further, the nanoparticles would not produce acid rain. 
Keith's proposal also has some disadvantages. First, the proposal has not been tested. The eruption of Mt. Pinatubo provides solid proof that Crutzen's idea would work, but it is not known whether the nanoparticles envisioned by Keith would behave as predicted. Second, like Crutzen's proposal, Keith's idea would stabilize global temperatures at higher $\mathrm{CO}_{2}$ levels, so it would not address the problem of ocean acidification, and it might impact precipitation patterns, temperature distribution, tropical storms, and winds. Third, there could be significant environmental and public health risks of spraying nanoparticles into the stratosphere, which are not well-understood at this point. We do not know how engineered nanoparticles would affect human beings and other species. Presumably, the nanoparticles could be inhaled. Would this cause respiratory problems? Would plants and animals absorb the nanoparticles? Would the nanoparticles persist in the environment? Would they bioaccumulate? Fourth, Keith's proposal could be prohibitively expensive. Though Keith provides some estimates for the costs per kilogram of engineered nanoparticles $(\$ 60 / \mathrm{kg})$, he does not say how much material would be needed to stabilize global temperatures [46]. At $\$ 60 / \mathrm{kg}$, two million metric tons (the amount of $\mathrm{SO}_{2}$ used in Crutzen's proposal) would cost $\$ 120$ billion. There would also be costs related to transportation and deployment.

\section{Objections to Geoengineering}

Although many environmental scientists have begun to investigate and explore various geoengineering proposals, there is also strong opposition from some scholars and scientists and environmentalists [45,47-50] and environmental groups, such as Greenpeace and Hands Off Mother Earth [51-53]. There is even a group called Coalition Against Geoengineering [54] and a website titled Stop Geoengineering [54-55]. Opposition ranges from strong skepticism to complete disapproval. Some opponents are against even conducting research on geoengineering.

\section{Pragmatic Critiques}

There are two different kinds of arguments against geoengineering: pragmatic critiques and - for want of a better term-ideological ones. Pragmatic critiques point out the practical difficulties with implementing geoengineering proposals. These critiques seek to raise awareness about problems related to environmental and public health risks, financial costs, and efficacy $[35,45,49,50]$. Various geoengineering proposals could have negative impacts on the environment or public health, which are not well understood at this point $[35,45]$. Some of these, such as acid rain, ocean acidification, depletion of the ozone layer, and disruption of weather patterns, were noted earlier. While some of these adverse outcomes might be relatively easy to control or reverse, others might not be [35]. Geoengineering schemes could also be very expensive to develop and implement. Crutzen theorized that his plan would cost $\$ 25-\$ 50$ billion per year, but this estimate may be low. Other plans, such as the use of physical and chemical systems to remove $\mathrm{CO}_{2}$ from the atmosphere, could be much more expensive [35]. Geoengineering proposals also might not be very effective at mitigating climate change. Some ideas, such as space-based reflecting systems, could take decades to implement [35]. As these proposals have not been tested, more research would be needed to determine whether they would work.

Another type of practical challenge relates to obtaining international cooperation to implement geoengineering $[35,49]$. This challenge is present in most climate-related actions. For example, the Kyoto agreement's major weakness is its inability to provide consensus of greenhouse gas emission limits, particularly with respect to developing versus developed nations [56]. Such cooperation may be even more difficult for geoengineering.

Suppose a country decided to implement one of the geoengineering proposals, such as spraying $\mathrm{SO}_{2}$ into the stratosphere. What would give the country authority to make a large- 
scale intervention into the Earth's climate? Would the country need to obtain permission from other countries? What if some objected? How would an international agreement on geoengineering be achieved? Should different countries work together in developing and implementing geoengineering proposals? Clearly, these and other important political questions must be answered before any large-scale geoengineering plan is implemented.

The principal concerns for all engineers are the public's safety, health and welfare. This means that any design must be scientifically sound, so that risks may be assessed objectively. Every design is an optimization among variables to achieve a desirable outcome. In this sense, every design is chaotic. That is, a small change at the outset can lead to outcomes that can be very different from those expected. Thus, a mistake can lead to unintended and unwelcomed results.

The chaotic and uncertain aspects of climate change strategies are illustrated by the phenomenon of forcing, i.e. the effectiveness of a particular gas to promote global warming (or cooling, as is the case with aerosols). Forcing is affected by persistent changes in the composition of the atmosphere brought about by changes in land use, release of contaminants, and other human activities. Radiative forcing is the change in the net vertical irradiance within the atmosphere. Radiative forcing is often calculated after allowing for stratospheric temperatures to readjust to radiative equilibrium, while holding all tropospheric properties fixed at their unperturbed values. Numerous factors may affect forcing, as shown in Figure 2 [57].

There is also much uncertainty about radiant gases (See Table 2). The effectiveness of $\mathrm{CO}_{2}$ as a global warming gas has been known for over 100 years, but the first useful measurements of atmospheric $\mathrm{CO}_{2}$ were not taken until 1957. The level of understanding of other gases varies but only the well-mixed greenhouse gases enjoy a high level of scientific understanding. Little is known about the cooling forcing, e.g. sulphate and carbon aerosols, as well as albedo [57].

Geoengineering affects very large systems, i.e. the atmosphere and hydrosphere, which always involve large uncertainties. Engineers typically take great care before "scaling up." A design may work quite well in the laboratory where variables are tightly controlled. But even in confined engineered systems with long technological track records, such as wastewater treatment plants, a small change in one variable can mean the difference between clean and untreated water leaving the plant. This is exacerbated geometrically when extending a project in time and space. Such lack of foresight and insufficient scientific certainty is an ethical problem:

The bottom line is that the things engineers do have consequences, both positive and negative, sometimes unintended, often widespread, and occasionally irreversible. Engineers who make bad decisions often don't know they are confronting ethical issues [58].

These and other uncertainties create many practical challenges for geoengineering. In response to these practical difficulties, many have argued for a precautionary approach $[32,35,59]$. According to these commentators, research on geoengineering should continue, but specific proposals should not be implemented unless we have good evidence concerning their safety, efficacy, and feasibility. Small-scale, low-risk geoengineering projects, such as reforestation or the use of physical or chemical processes to remove $\mathrm{CO}_{2}$, should be attempted prior to implementing large, risky projects, such as $\mathrm{SO}_{2}$ spraying or fertilizing the oceans. Plans should be developed to prevent or minimize harmful effects of geoengineering. Other methods for mitigating climate change should be pursued while geoengineering is under consideration. Geoengineering should not be viewed as a substitute for reducing greenhouse gas emissions, but as a strategy that can complement these efforts 
$[15,32,35]$. Additionally, international cooperation on geoengineering efforts should be sought [35].

Recently, the UK Engineering and Physical Sciences Research Council (EPSRC) was planning to field test a small-scale geoengineering project to determine whether spraying sulfur particles into the stratosphere (Crutzen's proposal) would mimic the cooling effects of volcanic activity. Although the test would have had virtually no impact on the environment or public health, there was fierce opposition from environmental groups and concerned citizens, and the test was halted. The research project has been postponed indefinitely and remains under review. Lessons learned from this episode are that it is important to seek public input and have an oversight plan in place before initiating even a small-scale geoengineering study [60].

\section{Ideological Critiques}

Geoengineering opponents have voiced several objections that can be regarded as ideological, rather than pragmatic, and they reject geoengineering even if practical difficulties can be overcome. Some critics argue that geoengineering should not be pursued because this will take away money, expertise, and political will from other strategies for mitigating global warming, such as reducing $\mathrm{CO}_{2}$ emissions [49]. This is a speculative argument with little basis in fact. If climate mitigation research and development (R \& D) were a zero-sum game, then it would follow that geoengineering R \& D would detract from other climate mitigation strategies. But climate mitigation $\mathrm{R} \& \mathrm{D}$ is not a zero-sum game: many different government agencies, companies, private foundations, interest groups, and individuals are devoting considerable time, effort, and energy to this problem. Some of these stakeholders have strong commitments to reducing greenhouse gas emissions and are not likely to devote substantial resources to geoengineering. Thus, there is little evidence that pursuit of geoengineering will detract from other methods of mitigating global warming.

Furthermore, it should not matter whether geoengineering detracts from other methods of mitigating global warming, as long as geoengineering can meet the practical challenges, mentioned above. Someone who is committed to mitigating global warming should be willing to accept any method that meets appropriate standards of safety, cost, and feasibility. We suspect, therefore, that the "geoengineering detracts from efforts to reduce $\mathrm{CO}_{2}$ emissions" critique ultimately rests on the view, voiced by many environmentalists, that we should prefer reductions in greenhouse gas emissions to other mitigation strategies.

Why should we prefer reduction in greenhouse gases to other forms of mitigation? One reason is that environmental policies should deal with the causes of global warming, not the symptoms $[47,49,50]$. While it is important to treat the underlying causes of global warming, this does not imply that we should ignore the symptoms. If a patient becomes obese as a result of overeating and under-exercising and develops Type II (insulin-resistant) diabetes and high blood pressure, a physician should encourage the patient to eat less and exercise more, but he should still treat the symptoms. Indeed, it would be unethical for a physician to refuse to treat these symptoms until the underlying causes are addressed. Likewise, one could argue that we should take effective action to address the symptoms of global warming, not just the causes, and that both forms of intervention (i.e. curative and symptom control) can be pursued at the same time.

Some critics of geoengineering also believe that we should reduce greenhouse gas emissions instead of pursuing other strategies because they believe that environmental policies should preserve or restore nature to an earlier, pre-industrial state [48]. This rationale is only appealing to radical environmentalists, since most people do not subscribe to the view that we should keep nature unchanged. Many different human activities, ranging from urban 
development to agriculture, disrupt nature. If we should restore the atmosphere to preindustrial levels, then, following this line of reasoning, we should also restore the rest of nature. Most people would not be willing to adopt such a perspective, since it sacrifices human interests for environmental protection and preservation.

Another criticism of geoengineering is that large producers of greenhouse gases could use it to their advantage by pursuing geoengineering instead of reducing greenhouse gases [51,52]. It may indeed be the case that geoengineering favors some industry interests, but this is not a good reason to avoid geoengineering research or interventions. For comparison, suppose someone argued that we should not conduct research on methods for early detection and treatment of lung cancer, because this research would promote tobacco industry interests. The tobacco industry could use the results of this research to its advantage by arguing that cigarette smoking is not as dangerous as some have claimed, because lung cancer can be detected early and treated. Even if the research favors industry interests, this would not be a good reason for refusing to initiate these studies, because preventing and treating lung cancer is an important public health goal that should be pursued regardless of the implications for the tobacco industry. Likewise, if geoengineering could be an effective means of mitigating climate change, then it should be studied and pursued, regardless of whether it might favor industry interests.

Opposition to geoengineering may also stem from an aversion to technological solutions to social problems. Many of the methods for mitigating global warming require people to change their behavior: to drive less, to use mass transit, to eat less meat, and to reproduce less. Geoengineering does not require us to change what many perceive to be unhealthy or undesirable behaviors and offers a technological solution to the problem of climate change. One reason why some people are skeptical of technological solutions to social problems is that they believe technology creates its own complications and difficulties [61]. We might solve one problem only to create another one. This type of opposition to geoengineering is actually a version of the pragmatic critique, discussed above, because it dwells on the risks of geoengineering. Another reason why some people are skeptical of technological solutions to problems is that they are generally opposed to post-industrial technology [62]. While the Amish and modern-day Luddites might embrace this viewpoint, most people do not. Opposition to geoengineering motivated by a general aversion to modern technology would also imply opposition to automobiles, telephones, airplanes, and computers.

That said, the scientific uncertainty of geoengineering is no small matter. Acceptable risk must be reconciled with sound engineering. How much risk is acceptable with respect to the chance for a positive outcome? One of the challenges of applying such a utilitarian model to engineering systems is that financial costs and benefits are often easier, or at least more straightforward, to calculate than other, nonmonetized, costs and benefits, and the nonmonetized costs are often not seen right away. Another problem in assigning value to a climate related utility is the need to consider the costs of not conducting the geoengineering solution. This may be rooted in fears of the potential Pandora's box of an unknown technology. If decisions are only made to avoid these problems, society exposes itself to opportunity risks. That is, if we inordinately avoid designs for fear of potential harm, we may forfeit benefits. The prominent opportunities may be better known in medical biotechnological venues, where deviations from standards of care are discouraged. However, this is also true for geoengineering. An overly precautionary approach toward something so time-sensitive and potentially irreversible as climate change could result in missed opportunities. 


\section{Conclusion}

As we have shown, the main argument for geoengineering is that it may be a useful method of mitigating global warming, since other types of mitigation, such as reduction of greenhouse gas emissions, have been unsuccessful and may continue to face significant social, political, and economic obstacles. There are two types of arguments against geoengineering: pragmatic critiques, which claim that geoengineering faces significant problems related to safety, cost, and efficacy; and ideological critiques, which assert that geoengineering should not be pursued even if these practical hurdles can be surmounted. Though we find the pragmatic critiques to be persuasive, we do not take the same view of the ideological ones, because they ultimately rest on controversial assumptions about environmental policy, technology, and industry. Thus, we recommend continued research on geoengineering and discussion of policy options and prospects for international cooperation. Specific geoengineering proposals should not be implemented there is good evidence concerning safety, efficacy, and feasibility, as well as a plan for oversight. International cooperation and public input should also be sought. Other methods for mitigating global warming should be aggressively pursued while geoengineering is under consideration. The promise of an engineering solution to global warming should not be used as an excuse to abandon or cut back current, climate mitigation efforts.

\section{Acknowledgments}

This research is the work product of an employee or group of employees of the National Institute of Environmental Health Sciences (NIEHS), National Institutes of Health (NIH), however, the statements, opinions or conclusions contained therein do not necessarily represent the statements, opinions or conclusions of NIEHS, NIH or the United States government.

\section{References}

1. Union of Concerned Scientists. Scientific consensus on global warming. 2011

2. Intergovernmental Panel on Climate Change. Climate change 2007: synthesis report. 2007

3. National Oceanic and Atmospheric Administration. NOAA: 2010 tied for warmest year on record. 2010

4. Vallero, DA. Environmental biotechnology: a biosystems approach. Elsevier Academic Press; Amsterdam: 2009.

5. National Aeronautics and Space Administration. Global climate change. 2010

6. Interagency Working Group on Climate Change and Health. A human health perspective on climate change. 2010

7. Patz, JA. Climate change. In: Frumkin, H., editor. Environmental health: from global to local. 2. John Wiley and Sons; New York: 2010.

8. Intergovernmental Panel on Climate Change. Climate change 2007: mitigation of climate change. 2007

9. Mann CC, Plummer ML. Forest biotech edges out of the lab. Science. 2002; 295:1626-1629. [PubMed: 11872814]

10. Goodland R, Anhang J. Livestock and climate change. 2009

11. Environmental Protection Agency. Opportunities to reduce greenhouse gas emissions through materials and land management practices. EPA 530-R-09-017. 2009

12. Hinrichsen, D. Population pressure. In: Frumkin, H., editor. Environmental health: from global to local. 2. John Wiley and Sons; New York: 2010.

13. Intergovernmental Panel on Climate Change. Climate change 2007: impacts, adaptation, and vulnerability. 2007

14. Wiley LF, Gostin LO. The international response to climate change: an agenda for global health. JAMA. 2009; 302:1218-1220. [PubMed: 19755701] 
15. Crutzen P. Albedo enhancement by stratospheric sulfur injections: a contribution to resolve a policy dilemma? Clim Change. 2006; 77:211-220.

16. Gardiner S. A perfect moral storm: climate change, intergenerational ethics, and the problem of moral corruption. Environ Values. 2006; 15:397-413.

17. Vesilind, PA.; Alastair, SG. Engineering, Ethics, and the Environment. Cambridge University Press; Cambridge, UK: 1998.

18. Congressional Budget Office. The economic effects of legislation to reduce greenhouse-gas emissions. 2009

19. Kreutzer D. The economic impact of cap and trade. Testimony before the Energy and Commerce Committee U S House of Representatives. 2009

20. Organization for Economic Cooperation and Development. The economics of climate change mitigation: policies and options for global action beyond 2012. 2011

21. Environmental Defense Fund. How cap and trade works. 2011

22. Rosenthal E. Climate change treaty, to go beyond the Kyoto Protocol, is expected by the year's end. The New York Times. 2009

23. Posner, GA.; Weisbach, D. Climate change justice. Princeton University Press; Princeton, NJ: 2010.

24. Stone R. Climate talks still at impasse, China buffs its green reputation. Science. 2010; 330:305. [PubMed: 20947734]

25. Dessler, A.; Parson, E. The science and politics of global climate change: A guide to the debate. Cambridge University Press; Cambridge, UK: 2006.

26. Spencer, RW. Climate confusion: How global warming hysteria leads to bad science, pandering politicians and misguided policies that hurt the poor. Encounter Books; New York: 2010.

27. Tollefson J. Climatic-change politics: The sceptic meets his match. Nature. 2011; 475:440-441. [PubMed: 21796181]

28. Mooney, C. The Republican war on science. Basic Books; New York: 2005.

29. Achenbach J, Eilperin J. Climate change science makes for hot politics. Washington Post. 2011

30. Schneider SH. Geoengineering: could-or-should-we do it. Clim Change. 1996; 33:291-302.

31. Keith DW. Geoengineering the climate: history and prospect. Ann Rev Energy Environ. 2000; 25:245-284.

32. Keith DW, Parson E, Morgan EG. Research on global sun block needed now. Nature. 2010; 463:426-27. [PubMed: 20110972]

33. Kintisch E. Climatic studies. Asilomar 2 takes small steps toward rules for geoengineering. Science. 2010; 328:22-23. [PubMed: 20360071]

34. Tollefson J. Geoengineering faces ban. Nature. 2010; 468:13-14. [PubMed: 21048732]

35. The Royal Society. Geoengineering the climate: science, governance, and uncertainty. The Royal Society; London: 2009.

36. Bodansky D. May we engineer the climate? Clim Change. 1996; 33:309-321.

37. Jamieson D. Ethics and Intentional climate change. Clim Change. 1996; 33:323-336.

38. Intergovernmental Panel on Climate Change. Carbon dioxide capture and storage: technical summary. 2005

39. Morton O. Climate change: is this what it takes to save the world? Nature. 2007; 447:132-136. [PubMed: 17495899]

40. Wigley TM. A combined mitigation/geoengineering approach to climate stabilization. Science. 2006; 314:452-454. [PubMed: 16973840]

41. Environmental Protection Agency. Sulfur dioxide. 2011

42. Bell, ML.; Samet, JM. Air pollution. In: Frumkin, H., editor. Environmental health: from global to local. 2. John Wiley and Sons; New York: 2010.

43. Lovett GM, Tear TH, Evers DC, Findlay SE, Cosby BJ, et al. Effects of air pollution on ecosystems and biological diversity in the eastern United States. Annals New York Acad Sci. 2009; 1162:99-135. 
44. Fabry VJ, Seibel BA, Feely RA, ORR JC. Impacts of ocean acidification on marine fauna and ecosystem processes. ICES J Mar Sci. 2008; 65:414-32.

45. Robock A. 20 reasons why geoengineering may be a bad idea. Bull Atom Scient. 2008; 64:14-18.

46. Keith DW. Photophoretic levitation of engineered aerosols for geoengineering. PNAS. 2010; 107:16428-16431. [PubMed: 20823254]

47. Keihl J. Geoengineering climate change: treating the symptom over the cause? Clim Change. 2006; 77:227-278.

48. Morton O. Why people disagree about geoengineering. 2009

49. Jamieson D. Can space reflectors save us? Why we shouldn't buy into geoengineering fantasies. 2010

50. Gardiner, S. Is "arming the future" with geoengineering really the lesser evil? Some doubts about the ethics of intentionally manipulating the climate system. In: Gardiner, S.; Caney, S.; Jamieson, D.; Shue, H., editors. Climate ethics: essential readings. Oxford University Press; New York: 2010.

51. Parr D. Geo-engineering is no solution to climate change. The Guardian. 2008

52. Greenpeace UK. Why geoengineering can't turn down the global thermostat. 2009

53. Hand Off Mother Earth. Ban geoengineering experiments. 2011

54. Coalition Against Geoengineering. 2011

55. Stop Geoengineering. 2011

56. Engelbeen F. Kyoto's shortcomings and other proposals. INFOTERRA. 2001

57. Intergovernmental Panel on Climate Change. Climate change: the scientific basis. 2001

58. Augustine N. Ethics and the second law of thermodynamics. The Bridge. 2002; 32:4-7.

59. Elliott K. Geoengineering and the precautionary principle. Intern J App Phil. 2010; 24:237-253.

60. Macnaughten P, Owen R. Environmental science: Good governance for geoengineering. Nature. 2011; 479:293. [PubMed: 22094673]

61. Weinberg, AM. Can technology replace social engineering?. In: Teich, AH., editor. Technology and the future. 5. St. Martin's Press; New York: 1990.

62. Drengson, AR. Four philosophies of technology. In: Hickman, LA., editor. Technology as a human affair. McGraw-Hill; New York: 1990. 


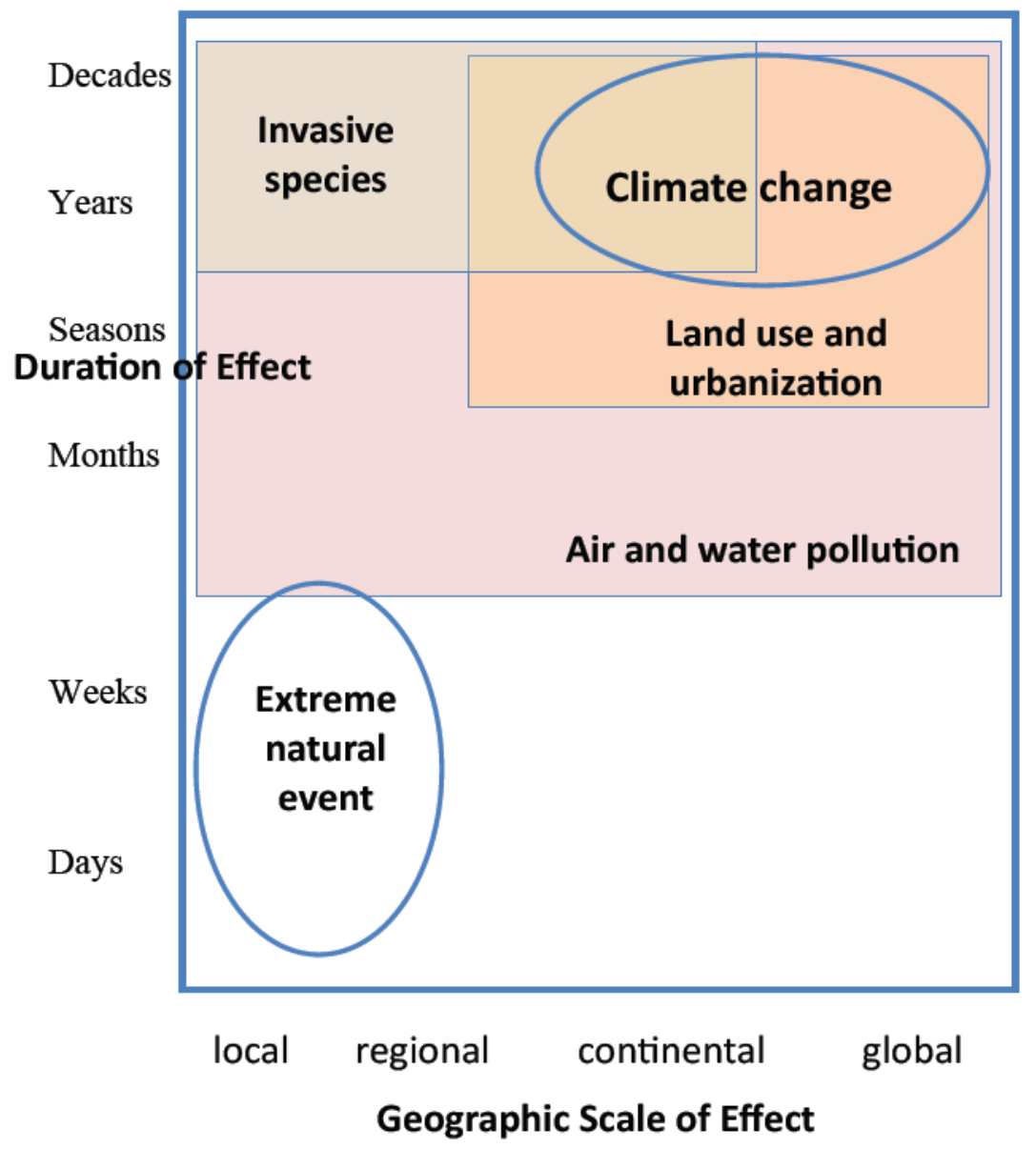

Figure 1.

The response to stressors has temporal and spatial dependencies. Near-field stressors can result from a spill or emergency situation. At the other extreme, global climate change can result from chronic releases of greenhouse gases with expansive (planetary) impacts in direct proportion to significant changes in global climate (temperature increases in the troposphere and oceans, shifting biomes, sea level rise, and migratory patterns). Adapted from: [4]. 


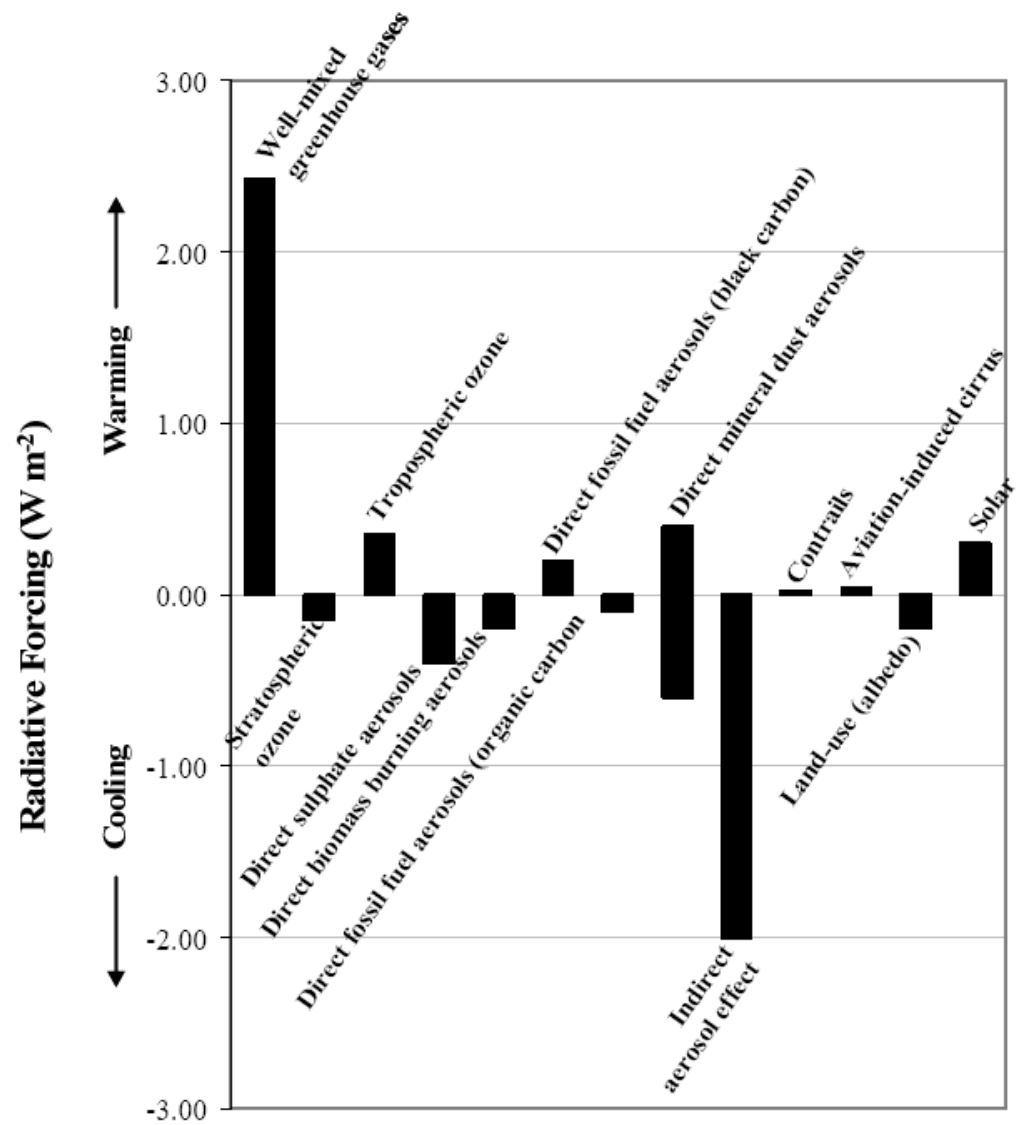

Figure 2.

The global mean radiative forcing (Watts per square meter, $\mathrm{W} \mathrm{m-2)}$ of the climate system for the year 2000, relative to 1750. The International Panel on Climate Change (IPCC) has applied a "level of scientific understanding" (LOSU) index is accorded to each forcing (See Table 2). This represents the Panel's subjective judgment about the reliability of the forcing estimate, involving factors such as the assumptions necessary to evaluate the forcing, the degree of knowledge of the physical/chemical mechanisms determining the forcing, and the uncertainties surrounding the quantitative estimate of the forcing. Based on [57]. 
Table 1

Geoengineering Proposals.

Solar radiation management

Spraying $\mathrm{SO}_{2}$ into the stratosphere enhance cloud albedo

Spraying engineering nanoparticles into the stratosphere to enhance cloud albedo

Placing reflective mirrors, discs, or particles in Earth orbit

Painting roofs and other structures with reflective material

Placing solar reflectors in the desert

Carbon dioxide removal

Using physical and chemical processes to remove and store $\mathrm{CO}_{2}$

Enhancing $\mathrm{CO}_{2}$ removal and storage by terrestrial plants

Burial of biomass

Reforestation and afforestation (creating new forests)

Fertilizing the oceans to stimulate $\mathrm{CO}_{2}$ removal by plankton 
Table 2

Level of scientific understanding (LOSU) of radiative forcings. Adapted from [57].

\begin{tabular}{|c|c|}
\hline Forcing Phenomenon & LOSU \\
\hline Well-mixed greenhouse gases & High \\
\hline Stratospheric O3 & Medium \\
\hline Tropospheric O3 & Medium \\
\hline Direct sulphate aerosols & Low \\
\hline Direct biomass burning aerosols & Very low \\
\hline Direct fossil fuel aerosols (black carbon) & Very low \\
\hline Direct fossil fuel aerosols (organic carbon & Very low \\
\hline Direct mineral dust aerosols & Very low \\
\hline Indirect aerosol effect & Very low \\
\hline Contrails & Very low \\
\hline Aviation-induced cirrus & Very low \\
\hline Land-use (albedo) & Very low \\
\hline Solar & Very low \\
\hline
\end{tabular}

